\title{
FUNGSI-FUNGSI MANAJEMEN DALAM PENGELOLAAN KURIKULUM
}

\section{Luthfiyyah Saajidah}

Madrasah Ibtidaiyah Terpadu Pesantren Persatuan Islam 24

Jl. Cikijing KM.1, 5, Linggar, Rancaekek, Bandung, Jawa Barat 40394

Email: saajidah.luthfiyyah24@gmail.com

\begin{abstract}
ABSTRAK
Penerapan fungsi-fungsi manajemen dalam pengelolaan kurikulum menjadi bagian peningkatan mutu lembaga pendidikan. Penelitian ini merupakan penelitian deskriptif, kualitatif yaitu metode. Peneliti mendeskripsikan temuan-temuan dari fenomena yang terjadi dilapangan dengan menggunakan teknik wawancara, observasi dan studi dokumentasi. MI Miftahul Huda perencanaan kurikulum dilakukan melalui dua tahapan yakni perencanaan kurikulum oleh divisi pendidikan dari yayasan kemudian perencanaan yang dilakukan oleh pihak madrasah. MI At-Taqwa dan MIT PERSIS 24 dilaksanakan oleh pihak Madrasah melibatkan Kepala Madrasah beserta Wakil, Dewan Guru, dan Komite Madrasah pada rapat pengembangan kurikulum. Pengorganisasian Kurikulum kurikulum berdasarkan mata pelajaran (subject curriculum). Penggerakan Kurikulum dilaksanakan melalui pelaksanaan pembelajaran Pengawasan Kurikulum di bagi kepada dua kategori yakni pengawasan terhadap Peserta Didik dan pengawasan terhadap Tenaga Pendidik.
\end{abstract}

Kata kunci: Fungsi-Fungsi Manajemen, serta Manajemen Kurikulum

\begin{abstract}
The application of management functions in managing the curriculum is part of improving the quality of educational institutions. This study is a descriptive, qualitative research method. The researcher describes the findings of the phenomena that occur in the field using interview techniques, observation and documentation studies. MI Miftahul Huda curriculum planning was carried out through two stages, namely curriculum planning by the education division of the foundation, then planning carried out by the madrasa. MI At-Taqwa and MIT PERSIS 24 are carried out by Madrasahs involving Madrasah Heads and Representatives, Teacher Councils, and Madrasah Committees at curriculum development meetings. Organizing curriculum curriculum based on subjects (subject curriculum). The mobilization of the curriculum is carried out through the implementation of Curriculum Supervision learning divided into two categories, namely supervision of Students and supervision of Educators.
\end{abstract}

Keywords: Management Functions, and Curriculum Management 


\section{PENDAHULUAN}

Salah satu cita-cita umat Islam Indonesia yang sering dikumandangkan para pemimpin umat menjelang kemerdekaan ataupun setelah kemerdekaan adalah adanya lembaga pendidikan yang mampu menyiapkan "calon ulama yang cendikia dan cendikia yang ulama". Dengan istilah lain menyiapkan anak didik yang dapat memadukan IPTEK dan IMTAK. Inilah harapan utama masyarakat pada Madrasah. Peraturan Pemerintah (PP) dan Perundangan mengakui "Madrasah sebagai sekolah umum yang berciri khas Islam". Kurikulum madrasah adalah sama dengan sekolah umum, plus ciri khas keIslamannya. Dengan kata lain, Madrasah mempersiapkan anak didiknya mampu dalam sains dan teknologi, tetapi tetap dengan identitas Ke-Islaman dengan ungkapan lain, madrasah sebagai sekolah umum yang berciri khas Islam yang mampu memadukan kekuatan IPTEK dan IMTAK (Supiana, 2008:46).

Oleh sebab itu kurikulum di Madrasah perlu dikelola dengan baik. Manajemen kurikulum merupakan suatu sistem pengelolaan kurikulum yang kooperatif, komprehensif, sistemik, dan sistematik dalam rangka mewujudkan ketercapaian tujuan kurikulum (Rusman, 2013:3). Manajemen kurikulum khususnya merupakan substansi manajemen yang utama disekolah. Prinsip dasar manajemen kurikulum ini adalah berusaha agar proses pembelajaran dapat berjalan dengan baik, dengan tolak ukur pencapaian tujuan oleh siswa dan mendorong guru untuk menyusun dan terus menerus menyempurnakan strategi pembelajaraanya (Dinn Wahyudin: 2014, 18).

Pengelolaan kurikulum di Madrasah Ibtidaiyah Miftahul Huda dimulai dari perencanaan yakni membentuk Tim Penyusun dan Pengembang Kurikulum Tingkat Satuan Pendidikan (KTSP), selanjutnya pengelolaan kurikulum dimulai dari penyelenggaraan rapat pengembangan kurikulum yang dihadiri oleh seluruh guru mata pelajaran, konselor, komite sekolah, nara sumber dan yayasan ( Surat Keputusan KTSP dan Berita Acara rapat pengembangan KTSP 10 Juli 2017). Permasalahan dalam pengelolaan kurikulum di Madrasah Ibtidaiyah Miftahul Huda, yakni tidak tersedianya surat undangan pengembangan KTSP dan berkas kurikulum yang tersedia hanya berkas kurikulum tahun pelajaran 2007-2008 (Studi Pendahuluan pada Rabu, 17 Januari 2018).

Pengelolaan Kurikulum di Madrasah Ibtidaiyah At-Taqwa dilaksanakan dimulai dari awal tahun melalui kegiatan rapat penyusunan kurikulum dan pengembangan KTSP. Permasalahan dalam pengelolaan Kurikulum di MI AtTaqwa adalah berkas agenda pengelolaan kurikulum dan kurikulum belum diperbaharui setiap tahun, yang tersedia yakni berkas kurikulum tahun 20112012 dan tahun 2015-2016 sedangkan berkas agenda pengelolaan kurikulum dan kurikulum baru yang sesuai dengan tahun ajaran 2017/2018 belum tersedia di Madrasah Ibtidaiyah At-Taqwa Kabupaten Bandung (Studi Pendahuluan pada selasa, 10 April 2018)

Pengelolaan kurikulum di Madrasah Ibtidaiyah Terpadu Pesantren Persatuan Islam 24 dilaksanakan mulai dari rapat penyusunan dan pengembangan kurikulum tahun ajaran baru. Terdapat beberapa masalah 
dalam pengelolaan kurikulum, yakni tidak tersedianya berkas agenda pengelolaan kurikulum serta berkas kurikulum yang belum diperbaharui (Studi Pendahuluan pada selasa, 10 April 2018)

Simpulan secara umum permasalahan yang terjadi pada tiga Madrasah Ibtidaiyah diatas adalah kelengkapan berkas administrasi kurikulum dan pengarsipan dokumen yang berkaitan dengan agenda pengelolaan kurikulum belum terlaksana secara baik dan tertib sehingga berkas tidak langsung tersedia ketika dibutuhkan.

\section{KAJIAN TEORI}

Menurut Mulyono, (2008: 22) dalam proses implementasinya, manajemen mempunyai tugas-tugas khusus yang harus dilaksanakan. Tugastugas khusus itulah yang biasa disebut sebagai fungsifungsi manajemen. Menurut George R. Terry, (George R Terry, 2009: 15) terdapat lima kombinasi fungsi fundamental manajemen dalam rangka mencapai tujuan. Kombinasi $A$ terdiri dari perencanaan (planning), pengorganisasian (organizing), memberi dorongan (actuating) dan pengawasan (controlling). Kombinasi B terdiri dari perencanaan, pengorganisasian, memberi motivasi (motivating) dan pengawasan. Kombinasi $\mathrm{C}$ terdiri dari perencanaan, pengorganisasian, staffing, member pengarahan (directing) dan pengawasan. Kombinasi $D$ terdiri dari perencanaan, pengorganisasian, staffing, memberi pengarahan, pengawasan, inovasi dan memberi peranan. Kombinasi $E$ terdiri dari perencanaan, pengorganisasian, memberi motivasi, pengawasan dan koordinasi. Dari kelima kombinasi tersebut dapat disaring menjadi tiga fungsi utama manajemen, yaitu perencanaan, pengorganisasian, dan pengawasan.

Perencanaan adalah proses kegiatan yang rasional dan sistemik dalam menetapkan keputusan, kegiatan atau langkah-langkah yang akan dilaksanakan di kemudian hari dalam rangka usaha mencapai tujuan secara efektif dan efisien (Mulyono, 25). Sedangkan perencanaan pendidikan adalah pemilihan fakta-fakta dan usaha menghubung-hubungkan antara fakta yang satu dengan fakta yang lain dalam aktivitas pendidikan, kemudian memprediksi keadaan dan perumusan tindakan kependidikan untuk masa yang akan datang yang sekiranya diperlukan untuk mencapai hasil yang dikehendaki dalam pendidikan (Hikmat, 2009: 101) Makna perencanaan yang digambarkan di atas mengandung arti; pertama, manajer/pimpinan memikirkan dengan matang terlebih dahulu sasaran (tujuan) dan tindakan berdasarkan pada beberapa metode, rencana, atau logika dan bukan berdasarkan perasaan.

$$
\text { Mengorganiasikan (organizing) merupakan suatu proses }
$$

menghubungkan orang-orang yang teribat dalam organisasi tertentu dan menyatupadukan tugas serta fungsinya dalam organisasi. Dalam prosesnya dilakukan pembagian tugas, wewenang, dan tanggungjawab secara terperinci berdasarkan bagian dan bidang masing-masing sehingga terintegrasikan hubungan-hubungan kerja yang sinergis, koperatif, harmonis, dan seirama dalam mencapai tujuan yang telah disepakati (Saefullah, 2012 : 22).

Controlling atau pengawasan dan pengendalian adalah salah satu fungsi manajemen yang berupaya mengadakan penilaian, mengadakan koreksi terhadap segala hal yang telah dilakukan oleh bawahan sehingga dapat diarahkan ke jalan yang benar sesuai dengan tujuan. Pengawasan yaitu 
meneliti dan mengawasi agar semua tugas dilakukan dengan baik dan sesuai dengan peraturan yang ada atau sesuai dengan deskripsi kerja masing-masing personal (Saefullah, 2012: 38) Pengawasan dapat dilakukan secara vertikal maupun horizontal, atasan dapat melakukan pegontrolan terhadap kinerja bawahannya, demikian pula bawahan dapat melakukan upaya kritik kepada atasannya. Cara demikian diistilahkan dengan sistem pengawasan melekat. Pengawasan melekat lebih menitikberatkan pada kesadaran dan keikhlasan dalam bekerja.

\section{METODE PENELITIAN}

Metode yang digunakan dalam penelitian ini adalah deskriptif, kualitatif yaitu metode yang bertujuan untuk mendeskripsikan masalah yang dihadapi secara rinci pada saat penelitian berlangsung. Peneliti menggunakan penelitian deskriptif dengan maksud mendeskripsikan suatu pengelolaan yang terjadi di suatu lokasi, dengan harapan dapat dijadikan contoh atau model pada lokasi lain yang faktor-faktornya sama dengan setting lokasi yang diteliti. (Sugiyono, 2009: 291).

Penelitian kualitatif yang digunakan di dalam penelitian ini memiliki ciriciri sebagai berikut: 1) Menggunakan pengukuran kualitatif terhadap data atau informasi yang dikumpulkan; 2) Data kualitataif berbentuk deskripsi rinci tentang situasi, orang, kejadian, interaksi dan tingkah laku yang dapat diamati, khususnya yang berkaitan dengan situasi yang mendukung fungsi manajemen ekstrakurikuler di madrasah; 3) Menggunakan pendekatan holistic atau menyeluruh, induktif, dan bergerak dari suatu fakta ke fakta yang lain sampai ditemukan gambaran umum tentang fungsi manajemen dalam kegiatan ekstrakurikuler; 4) pengumpulan data menggunakan kerangka konseptual dengan tujuan untuk membatasi fokus perhatian dalam melakukan penelitian. Menurut Moustakas, In devering evidence in phenomenological Investigations, the scientific researcher established and carries out a series of method and procedures that satisfiy the requirements of an organized, disciplined and systemic study (Irawan, 2015: 23 No 1 Vol 2)

Pendekatan yang digunakan dalam penelitian adalah pendekatan sistem (system approach).Pendekatan ini memungkinkan pendekatan yang bersifat deskriptif, eksplanatoris, dan komprehensif.Sifat pendekatan deskriptif berusaha menjawab "apa yang terjadi", sedangkan eksplanatoris menjawab "mengapa" dan "bagaimana". (Supiana, 2008: 78)

\section{HASIL DAN PEMBAHASAN \\ Perencanaan Kurikulum}

Perencanaan kurikulum berarti menentukan hal-hal yang berkaitan dengan kurikulum itu sendiri, dan sebelumnya apa yang harus dilakukan dan bagaimana melakukannya. Perencanaan kurikulum adalah proses manajerial dalam menentukan apa yang akan dikerjakan dan bagaimana mengerjakannya (Amri Yusuf Lubis, 2015: 17 No 3 Vol 1). Perencanaan kurikulum berfungsi sebagai pedoman atau alat manajemen yang berisi petunjuk tentang jenis dan sumber individu yang diperlukan, sumber biaya, tenaga, dan sarana yang diperlukan, sistem monitoring dan evaluasi, peran unsur-unsur ketenagaan untuk mencapai tujuan manajemen lembaga pendidikan (Rusman, 2012:21). 
Proses perencanaan kurikulum di Madrasah harus dilaksanakan secara kolaboratif, artinya mengikutsertakan personel Madrasah dalam semua tahapan perencanaan itu. Pengikutsertaan ini akan menimbulkan perasaan ikut memiliki (sense of belonging) yang dapat memberikan dorongan kepada guru dan personel Madrasah yang lain untuk berusaha agar rencana tersebut berhasil (Amri Yusuf Lubis, 2015:18 No 3 Vol 1).

Perencanaan kurikulum yang dilaksanakan oleh ketiga Madrasah Ibtidaiyah diatas sudah sesuai, karena perencanaan kurikulum dilaksanakan setiap tahunnya melalui rapat pengembangan kurikulum yang melibatkan personel Madrasah dalam setiap prosesnya. Beberapa pihak yang dilibatkan dalam kegiatan rapat pengembangan kurikulum, diantaranya adalah : Kepala Madrasah beserta Wakil Kepala Madrasah, Dewan Guru, dan Komite Madrasah/Madrasah.

Dalam rapat pengembangan kurikulum dibahas beberapa hal terkait kurikulum yang akan digunakan, Administrasi kegiatan pembelajaran serta Pembagian tugas wali kelas/guru kelas. Hasil dari rapat tersebut merupakan sebuah pedoman/ kurikulum yang dilaksanakan selama tahun ajaran berlangsung. Namun berdasarkan hasil penelitian, di Ml At-Taqwa dan MIT PERSIS 24 pembukuan hasil rapat berupa dokumen kurikulum tertulis belum di perbaharui sesuai dengan tahun ajaran yang berlangsung (2017-2018). Dokumen kurikulum yang ada terakhir tahun ajaran 2015-2016, yakni pada saat pelaksanaan akreditasi terakhir. Berbeda halnya dengan MI Miftahul Huda, dokumen kurikulum tahun ajaran 2017-2018 sudah tersedia hanya saja belum dalam bentuk bundel dokumen kurikulum masih berbentuk draft file kurikulum, yang akan di bundel saat tahun ajaran berakhir.

\section{Pengorganisasian Kurikulum}

Malayu S.P Hasibuan mendefinisikan pengorganisasian sebagai suatu proses penentuan, pengelompokkan, dan pengaturan berbagai macam aktivitas yang diperlukan untuk mencapai tujuan, menempatkan orang-orang pada setiap aktivitas, menyediakan alat-alat yang diperlukan, menetapkan wewenang yang secara relatif didelegasikan kepada setiap individu yang akan melakukan aktivitas-aktivitas tersebut (Badrudin, 2013:111).

Pengorganisasian kurikulum merupakan pola atau desain bahan kurikulum yang tujuannya untuk mempermudah siswa dalam mempelajari bahan serta mempermudah siswa dalam melakukan kegiatan belajar sehingga tujuan pembelajaran dapat dicapai secara efektif (Dinn Wahyudin, 2014:23). Organisasi kurikulum meliputi pembagian tugas yang jelas, organisasi mata pelajaran, alokasi waktu, dan lainnya (Amalia dan Nina, 2016:21 No 2 Vol 2).

Pengorganisasian kurikulum terdiri atas beberapa jenis, yakni: 1) kurikulum berdasarkan mata pelajaran (subject curriculum) yang mencakup mata pelajaran terpisah-pisah (separate subject curriculum), dan mata pelajaran gabungan (correlated curriculum), 2) kurikulum terpadu (integrated curriculum), yang berdasarkan fungsi sosial, masalah, minat, dan kebutuhan, berdasarkan pengalaman anak didik, dan 3) berdasarkan kurikulum inti (core curriculum) (Dinn Wahyudin, 2014:24).

Pengorganisasian kurikulum di tiga Madrasah tersebut, semuanya sama yakni kurikulum digolongkan berdasarkan pada kelompok mata pelajaran (Subject Kurikulum). Didalamnya dijabarkan mengenai kelompok mata 
pelajaran, kurikulum muatan lokal, serta muatan pengembangan diri peserta didik. Kemudian terdapat pembagian tugas yang jelas terkait guru kelas/guru wali kelas dan guru mata pelajaran. Kurikulum yang saat ini digunakan di Indonesia adalah Kurikulum 2013. Berdasarkan penelitian, ketiga Madrasah Ibtidaiyah diatas juga sudah mulai menggunakan Kurikulum 2013 meskipun belum semua mata pelajaran di pegang oleh guru kelas. Masih terdapat beberapa Mata Pelajaran yang terpisah. Oleh sebab itu, dalam memilih guru kelas diperlukan pertimbangan yang matang agar tujuan pendidikan dapat tercapai secara efektif dan efisien.

\section{Penggerakan Kurikulum}

Pembelajaran di kelas merupakan tempat untuk melaksanakan dan menguji kurikulum. Dalam kegiatan pembelajaran semua konsep, prinsip, nilai, pengetahuan, metode, alat, dan kemampuan guru diuji dalam bentuk perbuatan, yang akan mewujudkan bentuk kurikulum yang nyata (actual curriculum-curriculum in action) (Rusman, 2012:74). Pada pelaksanaannya kurikulum dibagi menjadi dua tingkatan yaitu pelaksanaan kurikulum tingkat Madrasah dan kelas. Pada pelaksanaan kurikulum tingkat Madrasah kepala Madrasah bertanggung jawab melaksanakan kurikulum dilingkungan Madrasah yang dipimpinnya. Kepala Madrasah berkewajiban melakukan kegiatankegiatan menyusun rencana tahunan, menyusun jadwal pelaksanaan kegiatan, memimpin rapat dan membuat notula rapat, membuat statistic dan membuat laporan. Pada pelaksanaan tingkat kelas pembagian tugas guru harus diatur secara administrasi untuk menjamin kelancaran pelaksanaan kurikulum lingkungan kelas (Ibrahim Nasbi , 2017 : 362 No 2 Vol I).

Berdasarkan Hasil penelitian, penggerakan kurikulum di tiga Madrasah Ibtidaiyah diatas telah berjalan dengan baik yakni diwujudkan dalam bentuk pelaksanaan pembelajaran, yang dimulai sejak rapat pengembangan, penyusunan rencana kerja/ program kerja, penentuan/pembagian guru kelas dan guru mata pelajaran, serta menyusun jadwal kegiatan pembelajaran. Jika dibagi secara terpisah, pelaksanaan kurikulum tingkah Madrasah di laksanakan melalui rapat pengembangan kurikulum yang didalam nya dibahas mengenai kurikulum seperti apa yang akan digunakan, penentuan jadwal kegiatan pembelajaran, serta penyusunan administrasi kelas seperti program tahunan dan program semerter. Sedangkan kurikulum tingkat kelas merupakan pelaksanaan dari hasil rapat pengembangan kurikulum yang telah disesuaikan dengan kalender pendidikan yang pemerintah tetapkan.

\section{Pengawasan Kurikulum}

Pengawasan kurikulum dalam peningkatan mutu pembelajaran dilaksanakan dengan dua cara, yaitu pengawasan langsung dan pengawasan tidak langsung. Pengawasan langsung merupakan pengawasan yang dilakukan oleh yayasan, kepala Madrasah serta pengawas Madrasah dari Dinas Pendidikan setempat. Melalui pengawasan tersebut kepala Madrasah dan pengawas pendidikan langsung mendatangi ruang kelas dan melakukan kegiatan monitoring terhadap pelaksanaan pembelajaran.sedangkan pengawasan tidak langsung merupakan pengawasan yang dilakukan kepala Madrasah pada waktu-waktu tertentu terhadap proses pembelajaran tanpa diketahui oleh para guru dan siswa (Fadillah dkk, 2018:31 No 1 Vol 2). 
Bentuk pengawasan kurikulum yang dilaksanakan oleh ketiga Madrasah Ibtidaiyah diatas sudah sesuai dengan teori, yakni ada pengawasan secara langsung dan pengawasan secara tidak langsung. Madrasah Ibtidaiyah Miftahul Huda melaksanakan kedua bentuk tersebut, yang pertama pengawasan secara langsung yang dilaksanakan oleh kepala Madrasah dan divisi pendidikan dari pihak yayasan. Serta pengawasan tidak langsung di MI Miftahul Huda adalah pengontrolan secara tidak sengaja dilakukan oleh Kepala Madrasah ataupun Wakil Kepala Madrasah Bidang Kurikulum.

Madrasah Ibtidaiyah At-Taqwa melaksanakan kegiatan pengawasan yang sama yakni kegiatan pengawasan secara tidak langsung yang setiap harinya dilakukan oleh Kepala Madrasah atau disesuaikan dengan program kerja yang dibuat oleh Kepala Madrasah. Sedangkan pengawasan secara langsung dijadwalkan 3 bulan sekali, akan tetapi dalam realitas nya hal tersebut tidak terlaksana secara maksimal dan tidak terdokumentasi. Sedangkan di madrasah Ibtidaiyya Pesantren Persatuan Islam 24 pengawasan secara tidak langsung dilaksanakan melalui kegiatan pengontrolan yang dilakukan oleh Kepala Madrasah setiap harinya, namun ada kegiatan pengawasan rutin yang dilaksanakan 1 bulan sekali terkait prestasi peserta didik. Pengawasa secara langsung di MIT PERSIS 24 dilaksanakan namun terkait pelaksanaan supervisi secara langsung tidak terdokumentasi.

\section{SIMPULAN}

Perencanaan kurikulum dilaksanakan melalui rapat pengembangan kurikulum yang dilaksanakan sebelum tahun ajaran baru dimulai dengan melibatkan Kepala sekolah beserta dewan guru dan komite sekolah. Pengorganisasian kurikulum dilaksanakan melalui pembagian tugas guru dan penyusunan pola desain pada kurikulum yang digunakan. Penggerakan kurikulum diwujudkan dalam bentuk pelaksanaan pembelajaran, yang dimulai sejak rapat pengembangan kurikulum, penyusunan rencana kerja/ program kerja, penentuan/pembagian guru kelas dan guru mata pelajaran, serta menyusun jadwal kegiatan pembelajaran. Pengawasan kurikulum dilaksanakan secara langsung dan tidak langsung.

\section{REFERENSI}

Amilda dan Nina Wati. (2016). Manajemen Kurikulum Pendidikan Agama Islam (PAI) Di Sekolah Dasar IslamTerpadu (SDIT) Harapan Mulia Palembang. Jurnal of Islamic Education Management, Vol 2 No 2.

Amri Yusuf Lubis. (2015). Pelaksanaan Manajemen Kurikulum Pada SMA Negeri 1 Buengcala Kabupaten Aceh Besar. Jurnal Administarasi Pendidikan Pasca Sarjana Universitas Syiah Kuala, Vol 3 No 1.

Badrudin. (2013). Dasar-Dasar Manajemen, Bandung: Alfabeta.

Dinn Wahyudin. (2014). Manajemen Kurikulum, Bandung: Rosda Karya

Fadillah Dkk. (2018). Implementasi Manajemen Kurikulum Dalam Meningkatkan Kualitas Pembelajaran Di SMP Wiraswasta Batang Kuis Deli Serdang, Jurnal At-Tazakki. Vol 2 No 1.

Hikmat. (2009). Manajemen Pendidikan. Bandung: Pustaka Setia. 
Ibrahim Nasbi (2017). Manajemen Kurikulum: Sebuah Kajian Teoritis, Jurnal AlIdarah Vol 1 No 2.

Irawan dan Philip Buckley (2015). The Scientific Paradigm of Islamic Education Manageme: Phenomenology Perspective, JPI Vol 2 No 1.

Mulyono. (2008). Manajemen Administrasi dan Organisasi Pendidikan. Yogyakarta: Ar Ruzz Media.

Rusman (2013). Manajemen Kurikulum. Bandung: PT. Raja Grafindo.

Saefullah U. (2012). Manajemen Pendidikan Islam. Bandung: CV. Pustaka Setia.

Sugiyono (2012). Metode Penelitian Kuantitatif, Kualitatif dan R\&D, Alfabeta: Bandung.

Supiana. (2008). Sistem Pendidikan Madrasah Unggulan: di Madrasah Aliyah Negri Insan Cendikia Tangerang, Madrasah Aliyah Negri 1 Bandung, dan Madrasah Aliyah Negri Darussalam Ciamis. Jakarta: Badan Litbang Dan Diklat Departemen Agama RI.

Terry. George R. (2009). Prinsip-Prinsip Manajemen, Alih bahasa oleh J. Smith. D.F.M. Jakarta: Bumi Aksara. 